Revista de la red interuniversitaria de estudios sobre las literaturas rioplatenses contemporáneas en Francia

$9 \mid 2013$

Homenaje a Ana María Barrenechea

\title{
María Elena Walsh y Juan Ramón Jiménez : desencuentros y encuentros
}

\section{Fernando Copello}

\section{OpenEdition}

\section{Journals}

Edición electrónica

URL: http://journals.openedition.org/lirico/1197

DOI: $10.4000 /$ lirico. 1197

ISSN: 2262-8339

Editor

Réseau interuniversitaire d'étude des littératures contemporaines du Río de la Plata

\section{Referencia electrónica}

Fernando Copello, «María Elena Walsh y Juan Ramón Jiménez : desencuentros y encuentros », Cuadernos LIRICO [En línea], 9 | 2013, Puesto en línea el 01 septiembre 2013, consultado el 01 mayo 2019. URL : http://journals.openedition.org/lirico/1197 ; DOI : 10.4000/lirico.1197

Este documento fue generado automáticamente el 1 mayo 2019.

\section{cc) $(7)$}

Cuadernos LIRICO está distribuido bajo una Licencia Creative Commons Atribución-NoComercialSinDerivar 4.0 Internacional. 


\title{
María Elena Walsh y Juan Ramón Jiménez: desencuentros y encuentros ${ }^{1}$
}

\author{
Fernando Copello
}

1 La relación entre la juglaresa porteña y el poeta de Moguer ha sido evocada de manera desigual en las biografías de ambos autores.

2 Los textos dedicados a Juan Ramón Jiménez, a su obra, a su relación extremadamente profunda con el continente americano -que el poeta aprende a conocer a través de su temprano acercamiento a Rubén Darío (Palau de Nemes 1957 : 56-64) ${ }^{2}$ y que se transforma en su lugar de residencia durante la larga temporada de su exilio- son muy parcos en cuanto a su contacto con María Elena Walsh. Un trabajo rico y noticioso de Carmen Morán Rodríguez, titulado «Juan Ramón en Hispanoamérica », publicado en 2006, nos deja una visión apresurada, apenas una referencia a la escritora de Ramos Mejía :

También durante su viaje a Argentina y Uruguay realizó una selección de joven poesía, pensada para lecturas públicas, pero siempre con la idea de que después este material se recogiese en una publicación [...] Entre los poetas escogidos, algunos habían alcanzado ya cierto reconocimiento (por ejemplo, Daniel Devoto, María Granata, María Elena Walsh, Enrique Molina o Vicente Barbieri); otros, de nuevo, son desconocidos o prácticamente (Morán Rodríguez 2006 : 474).

Mucho más se había detenido en este encuentro Graciela Palau en su Vida y obra de Juan Ramón Jiménez. Sin embargo, la visión de Graciela Palau es algo imprecisa :

Durante su estancia en la Argentina los Jiménez recomendaron la adjudicación de una beca a una de las poetisas jóvenes argentinas de más promesa, María Elena Walsh, quien pasó una temporada como huésped del poeta y su esposa en Riverdale, cultivándose en Washington y en la Universidad de Maryland bajo su tutela. De vuelta a la Argentina, María Elena Walsh publicó un libro de versos y después inició una jira artística por Europa (Palau de Nemes 1957 : 329).

En realidad, fue más una invitación que una beca lo que los Jiménez propusieron a María Elena Walsh, cuyo primer libro de poemas, Otoño imperdonable, había sido publicado en 1947. Los Jiménez llegaron a Buenos Aires el 4 de agosto de 1948 a bordo del "Río Juramento" $\mathrm{y}$ en el puerto los esperaba un grupo de estudiantes, entre los cuales se 
hallaba nuestra autora. Una fotografía recuerda este encuentro durante el frío invierno porteño : el creador de Platero y yo nos mira enmarcado en el centro ; desde la izquierda lo observa curiosa e intrigada María Elena Walsh. Esta mirada es absolutamente significativa y dice lo que no dicen las palabras. Para nosotros, hoy, es la mejor introducción al tema que deseo evocar. ${ }^{4}$

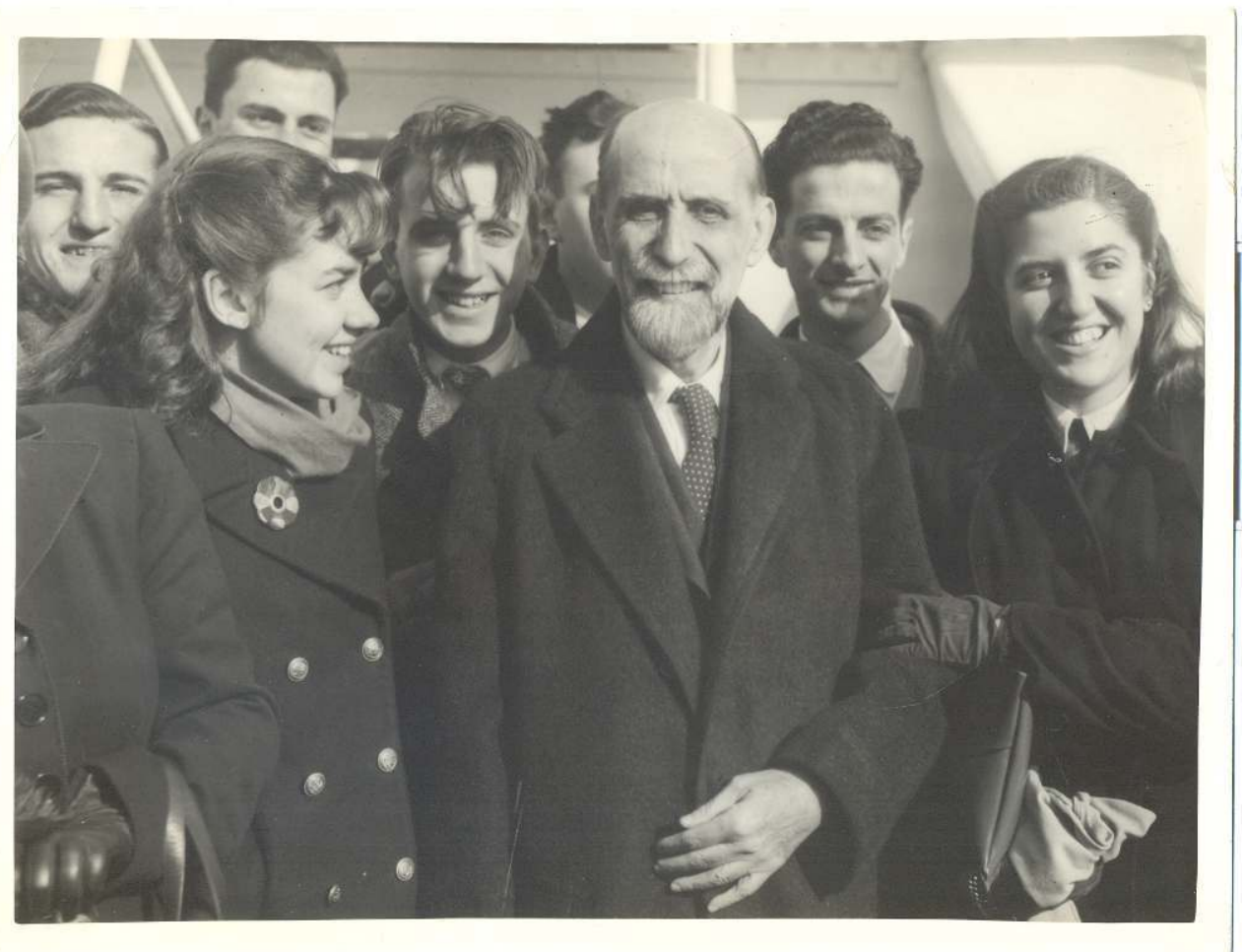

Viaje a Argentina de Juan Ramón Jiménez

Sala Zenobia y Juan Ramón Jiménez. Sistema de Bibliotecas. Universidad de Puerto Rico. Recinto de Río Piedras.

5 Antes de dejar Buenos Aires, el 13 de noviembre de 1948, el poeta andaluz invitó a María Elena Walsh y a Horacio Armani a pasar una larga temporada en su casa de Maryland. Así lo recuerda Antonio Requeni en un artículo publicado en 1982 con motivo del centenario del nacimiento de Jiménez :

Pero no terminó ahí la generosidad de Juan Ramón Jiménez en la Argentina. Antes de irse (el 13 de noviembre) invitó a los poetas María Elena Walsh y Horacio Armani a pasar una temporada en su casa de Maryland. Armani no pudo ir por hallarse su madre gravemente enferma, pero María Elena vivió cinco meses con Juan Ramón y Zenobia (Requeni 1982. También en Requeni 2008 : 721).

Evidentemente, poco es lo que sabemos sobre cómo vivió Juan Ramón esos cinco meses compartidos con la creadora de Hecho a mano, cuya educación tomó sumamente en serio. Quizá la autobiografía inédita del escritor de Moguer, que ahora preparan Mercedes Juliá y María Ángeles Sanz Manzano, nos dé nuevos datos que sería interesante investigar (Álvarez Pla 2013).

7 Esta breve introducción nos servirá, de todos modos, de puerta de entrada hacia lo que debería ser el centro de mi propuesta : evaluar la huella que deja el autor de Platero y yo en la escritora de Dailan Kifki. Pienso encarar mi escrito articulándolo en dos partes : evocar primero los testimonios de María Elena Walsh sobre su encuentro y relación personal e 
intelectual con el escritor de Moguer ; luego, estudiar los rastros posibles que de Jiménez quedan en la producción amplia (y que no es solamente literaria) de la juglaresa de Buenos Aires.

8 La entrada en materia es evidentemente compleja porque la relación entre ambos escritores no parece haber sido sencilla. Queda por momentos un gusto amargo. Lo cierto es que la Walsh nunca evitó decir su dificultad de relación y su visión ambivalente con respecto al andaluz universal y ello, de manera particularmente clara, en el artículo que le dedica en Sur, publicado en 1957 : «Juan Ramón Jiménez, Premio Nobel » (Walsh 1957 : 1-4). Evocan la cuestión Ilse Adriana Luraschi y Kay Sibbald en el ensayo más importante que se ha dedicado a la escritora (Luraschi y Sibbald 1993):

Tal como ella misma declara, la 'implacable línea de exigencia' juanramoniana casi silencia para siempre a la joven poeta ; sin embargo, a pesar de esta influencia más bien demoledora, llega a valorar en él particularmente 'su desdén por el salón y el privilegio, su sincera complicidad con los desprotegidos'... (p. 23)

En este contexto complejo, lo que sí podemos afirmar es que María Elena Walsh no olvidó nunca la presencia de Juan Ramón en su vida, que su recuerdo vuelve constantemente en sus escritos a lo largo de los años, incluso en uno de sus últimos textos, Fantasmas en el parque, publicado en 2008 (Walsh $2008 \mathrm{~b}:$ 178-186). ${ }^{5}$ Todo ello prueba la permanencia de una huella que merodea en su obra y en su biografía. Convendría, por lo tanto, hacer una lectura cronológica de las referencias a Juan Ramón Jiménez.

10 El primer texto con el que contamos es del mismo año 1949; se titula "Carta de Maryland » y fue publicado en El Hogar. ${ }^{6}$ Aparece allí una visión extremadamente idílica de la llegada de María Elena a Washington :

...por fin, llegué a la blanca Washington, donde me esperaban Juan Ramón Jiménez y Zenobia, llenos de sonrisas y preguntas. Recorrimos en auto las calles anchas y abiertas, las iluminaciones de Año Nuevo [...] Después, entre oscuras filas de olmos, llegamos a Riverdale, a este barrio tranquilo de Maryland, donde Juan Ramón vive sus intensos días de trabajo y amor. Aquí me esperaba, en la casita blanca, un interior tibio con leños ardiendo, viejas presencias de libros y bellos pedazos de España. Mi cuarto tiene alegres ventanas, adonde vienen las ardillas a visitarme curiosamente (p. 88).

11 Por detrás de esta descripción se esconde el comienzo de una parálisis poética que así se refleja en una conversación mantenida en 1987 con Ilse Luraschi y Kay Sibbald : « ...fue una época muy paralizante para mí, primero por la presencia de Juan Ramón, un personaje duro, muy sarcástico, muy cruel, y después porque el contacto con la sociedad de consumo [...] era una fuente de gran angustia » (1993 : 25, nota 44). Una conversación mantenida con Alicia Dujovne casi diez años antes matiza esta impresión y nos da, creo yo, una imagen más completa de lo que fue esa experiencia norteamericana :

JRJ me recomendó a la Universidad de Maryland y allí asistí aburrida a algunas clases. No era mi lugar de aprendizaje. Mi verdadero maestro era él, que una vez me llevó a visitar a Ezra Pound, por entonces prisionero en un instituto psiquiátrico [...] y JR me aconsejó ir a visitar a Pedro Salinas [...] Y fue JR quien me mandó una vez, sola, a conocer Nueva York, que recorrí de cabo a rabo durante una insólita semana. Y fue él quien puso unos billetes en mi mano diciéndome : Ésta es mi invitación para que vayas a escuchar a Horowitz, al Carnegie Hall, y a Rubinstein, y al chelista Piatigorsky. Además, ecléctico igual que mi padre, me recomendó ir a Radio City y me explicó detalladamente los méritos de las Rockettes, el famoso cuerpo de bailarinas del inmenso music-hall [...] De esta escueta lista se deduce que el maestro no daba cátedra sobre banalidades ni personajes secundarios. Jamás reví con desdén ni rechacé ninguna de sus enseñanzas, y algunas fueron duras, despiadadas y tan 
drásticas que llegaron a paralizarme. Así es, éste fue mi bachillerato, del que no regresé contenta, con un diploma bajo el brazo sino, como siempre, perpleja, pensando que el mundo era ancho, ajeno, bellísimo y amenazador (Dujovne 1982 :

39-40).

12 Este reconocimiento de un bachillerato particularmente original (aunque difícil) es lo que explica el deseo de María Elena Walsh de recordar y de reeditar en obras diversas su artículo publicado en Sur en 1957, como texto individual en Desventuras en el País-Jardín-deInfantes en 1993 (p. 106-109) y, más tarde, completando un capítulo, en Fantasmas en el parque en 2008 (p. 182-186). Ese artículo de Sur nos dará pautas importantes para el análisis de la obra de la escritora de El reino del revés, pero antes de abordarlo creo importante transcribir un poema del libro Hecho a mano que sintetiza desde la misma arcilla creadora y con menos filtros la experiencia de Riverdale :

Postal detenida

Voy a contarte todo.

Espera que recuerde.

Había nieve y Juan Ramón callaba.

Había Juan Ramón, callaba nieve.

Yo no podía más

de adolescente.

Supongo que el crepúsculo invadía su barba y sillas locas de papeles.

No, no hay fotografías

donde me encuentres.

Zenobia era de risa y sombrerito.

Pura eficacia, método celeste.

Hace ya tanto tiempo

en 1949.

Él decía sonidos oxidados

desde un aljibe, trabajosamente.

Riverdale de madera

de juguete.

Ella monologaba con cristales.

Él atendía túneles ausentes.

Yo no supe

qué hacer, dónde ponerme.

Llegué una noche y Juan Ramón estaba

mirándose por dentro, como siempre...

Es inútil.

Me duele (Walsh [1965] 1999 : 57-58).

13 Este poema, escrito probablemente alrededor de 1965, es decir unos quince años después de la experiencia de Riverdale, y seguramente a la luz de la experiencia analítica ${ }^{7}$, 
muestra la dificultad existencial que significó compartir el universo de Juan Ramón y Zenobia en el marco del exilio. En esa posición dolorosa, primero paralizante y ello de manera duradera, se fueron gestando, a mi modo de ver, elementos enriquecedores que van a desparramarse luego en amplia creatividad.

Corresponde ahora una lectura, que será parcial, de «Juan Ramón Jiménez. Premio Nobel ", el artículo publicado en Sur. ¿Por qué parcial ? Porque no voy a detenerme en los comentarios dolorosos que expresa mejor « Postal detenida " y sí trataré de extraer el jugo más fértil. ${ }^{8}$

El texto de Sur, en el que no se habla en ningún momento de la atribución del Premio Nobel, muestra en la autora un deseo de ir a lo substancial, a la médula, evitando todo protocolo. Ocupa cuatro páginas en la revista dirigida por Victoria Ocampo, páginas que se subdividen en seis subcapítulos : « Presencia y diálogo », " Maryland, 1949 », " Él y los demás », «Soledad con acústica », «Espíritu folklórico 》 y «Él y nosotros ». Los tres primeros evocan la dificultad en la relación y culminan con una frase de síntesis : "Yo elijo la fidelidad hacia su persona y su poesía, porque las considero ejemplares más allá de las sombras que nos arroje su conducta de crítico feroz y de difícil amigo » (p. 2). A partir del cuarto subcapítulo aparecen mencionadas las virtudes del andaluz, en abierta sintonía con la sabiduría del pueblo y lo musical. Curiosamente, es la María Elena que ya integra desde hace años el dúo Leda y María ${ }^{9}$ quien acentúa ciertas nociones y ve ahora lo que ya es en ella, a mi parecer, herencia juanramoniana. Vayan aquí algunos fragmentos : « Juan Ramón vive su tiempo, tanto como revive amorosamente los seres y los gestos de su pueblo... » (p. 3) ; « Una especie de pureza primitiva lo acerca a lo sencillo, aunque a veces ese acercamiento se produzca de tortuosas maneras» (p. 3) ; "...Juan Ramón es un espíritu folklórico. Y quiero reivindicar esta palabra no pocas veces desprestigiada... » (p. 3) ; « [como todo español] ... está nutrido de España, sucio de tierra española, abarrotado de coplas, con una guitarra derretida en la sangre, con un juego ancestral que asoma hasta en sus mayores disimulos » (p. 4).

Ese peso de lo telúrico, de lo tradicional y no institucionalizado que Juan Ramón respeta, admira e integra en su literatura -a través de un camino tortuoso que lleva a la sencillezes justamente un mecanismo que la misma María Elena Walsh va a poner en práctica. Así lo explica de manera concisa e indudable Olga Fernández Latour de Botas en Folklore y poesía argentina :

...lo mismo ocurre con algunas composiciones de una de las más inteligentes escritoras argentinas del presente, María Elena Walsh (Tutú Marambá) quien, estilizando formas y usando temas perfectamente ubicables en el ámbito jujeño, ha creado poemas para niños: piezas exquisitas, llenas de gracia, cosquilleantes de humor feliz (Fernández Latour de Botas 1969 : 247, el subrayado es nuestro).

17 Ahora bien, ¿es la María Elena Walsh de 1957 quien ve el valor del acercamiento al folklore gracias al aprendizaje junto a Leda Valladares? ¿o es una herencia juanramoniana la que preparó la rica experiencia llevada a cabo junto a la folklorista tucumana? Alguna respuesta hay en las líneas finales del artículo de Sur :

Amaba [Juan Ramón] a nuestro pueblo [latinoamericano] a través de su música, de unos discos que sonaban a diario en la casita de Riverdale. Alguna vez me hizo avergonzar de mi desabridez telúrica. Siempre le agradeceré esa invitación a la conciencia, que me ha refundido las raíces, y que trataré de ahondar toda la vida. Ningún escritor nos ha dado más existencia, como pueblo sospechado y como literatura escondida (y eso que no tuvo ocasión de decir piedra libre a las coplas de bagualas... (p. 4). 

imperdonable a Hecho a mano. Es cierto que el mayor peso lo tiene sin duda el acercamiento a Leda Valladares, pero Juan Ramón, de algún modo, preparó ideológicamente dicho acercamiento. Elena Walsh a Platero y yo en el repertorio de la literatura juvenil. En una conferencia pronunciada en $1964^{10}$ dedicada a la literatura infantil, la autora de Dailan Kifki menciona a quienes considera los dos más grandes poetas para niños que hayan existido: Lewis Carroll y Edward Lear (p. 123). Los considera « sabios ladrones de la tradición ». Menciona luego al creador de Chantefables, Robert Desnos (p. 123). Y lamenta que las buenas intenciones de Gabriela Mistral hayan dado un resultado torpe (p. 123). En cuanto a la literatura infantil en lengua castellana, admira a José Sebastián Tallon (p. 124). Ahora bien, ¿qué es lo que explica tanto silencio con respecto a Platero y yo cuyo autor, como Lewis Carroll y Edward Lear, fue también un sabio ladrón de tradiciones, lo que reconoce la juglaresa cuando dice en Sur que la obra de Jiménez es « folklore español »? Pienso en dos explicaciones posibles. Por un lado, María Elena Walsh considera que la tradición española « tiene caractérísticas sombrías, un eco casi constante de lobreguez » (p. 125), lo que sin duda es poco recomendable para niños. Luego, hay que considerar que Platero y yo, tan editado, tan traducido, tan difundido, tan asociado a la escuela, ha perdido su chispa, su encanto inicial. ${ }^{11}$

21 En la Argentina de los años 60, María Elena Walsh quiere proponer una literatura infantil nueva, renovadora. Mencionar a Jiménez no sería una buena estrategia. Sin embargo, la transformación de Platero y yo en libro juvenil, la incorporación natural hacia 1914 de un texto poético en el mercado de la infancia no pudo estar completamente ausente como idea o como sugerencia en el momento en que María Elena Walsh se lanza a la conquista de un género y de un nuevo público. Por eso no nos llama la atención el elogio de Platero y yo en el texto publicado en Sur, que enuncia la que seguramente fue para ella la mejor herencia del escritor de Moguer.

Creo que valdría la pena, a modo de transición, y antes de pasar revista de manera más concreta a la obra de la escritora de Ramos Mejía, detenernos en una percepción rápida de la elegía consagrada al asno andaluz. ${ }^{12}$ Como se sabe, Jiménez no imaginó inicialmente a Platero y yo como libro destinado a la infancia, aunque su creación esté íntimamente ligada a los años pasados en contacto con la Institución Libre de Enseñanza, que lo aproximaron a una nueva pedagogía, y a las enseñanzas de Francisco Giner de los Ríos. ${ }^{13}$ Cuando Francisco Acebal, director de la editorial La Lectura le pidió una selección para la colección Biblioteca de Juventud, Jiménez eligió en su manuscrito 63 capítulos, evitando los más tristes (a pesar de ello, una atmósfera de melancolía habita incluso esta versión infantil). La edición abreviada para chicos (1914) será seguida por la edición completa (1917). Sin embargo, las dos variantes continúan existiendo. ${ }^{14}$ Otro elemento que se debe

Cuadernos LIRICO, 9 | 2013 
tener en cuenta es que Platero y yo ha sido, casi siempre, un libro ilustrado. Jiménez nunca renegó de la atribución de su libro a la literatura infantil, muy por el contrario. A pesar de ello, la percepción «seria » de su obra, la mirada académica, lo asocia a sus libros de poesía, cuyo valor es innegable también. Sin embargo, María Elena Walsh, al festejar sobriamente la atribución del Premio Nobel, define a Juan Ramón como el autor de Platero . Y pienso entonces en unos comentarios de Ilse Luraschi y Kay Sibbald. Nos dicen : « En uno de sus ensayos sobre Baudelaire, Walter Benjamin habla del 'arte de estar fuera del centro'... »; para las autoras este concepto puede explicar una estrategia femenina en la Walsh, una estética descentrada (Luraschi y Sibbald 1993 : 168-169), que asocian también (y eso es lo que me interesa) a los subgéneros de difusión masiva. Creo que tanto Juan Ramón como María Elena aceptan entrar en una relación diferente con el público, a través en efecto de una estética descentrada que barre una serie de criterios literarios jerárquicos para aceptar las leyes del mercado. Y no puedo olvidar al Jiménez editor en sus años de la Residencia de Estudiantes, al Jiménez preocupado por la tipografía y las ilustraciones del libro, a alguien muy en contacto con lo concreto (Palau de Nemes 1956 : 156-166 ; 176-183). El tema daría para más y no es ésta la ocasión.

Lo cierto es que Platero y yo es una obra revolucionaria. ${ }^{15}$ Es revolucionaria por su tema : la amistad y el parentesco entre el hombre y el animal, el mutuo respeto, el rechazo de una jerarquía entre las especies, la idea (muy de la Institución Libre) de la riqueza en un acercamiento a lo natural. Es revolucionaria porque barre la estética del hombre montado a caballo, del héroe que domina a la bestia y desde su altura salva y ayuda a los demás sin olvidar su privilegio. El poeta y el asno van uno junto al otro, se acompañan y, a veces, cuando el poeta monta a Platero se funde en una misma identidad. ${ }^{16}$ Hay además en Platero y yo una aproximación a lo viril que incluye la delicadeza y que constituye un modelo nuevo de la posible relación entre los sexos. ${ }^{17}$ Hay, también, como era de esperar, una percepción de la literatura como juego, ajena a todo propósito didáctico, como se ve en el capítulo titulado « La fábula »:

Desde niño, Platero, tuve un horror instintivo al apólogo, como a la iglesia, a la guardia civil, a los toreros y al acordeón [...] Hombre ya, Platero, un fabulista, Jean de la Fontaine, de quien tú me has oído tanto hablar y repetir, me reconcilió con los animales parlantes [...] Pero siempre dejaba sin leer la moraleja, ese rabo seco, esa ceniza, esa pluma caída del final. [...] Así, no temas que vaya yo nunca [...] a hacerte héroe charlatán de una fabulilla, trenzando tu expresión sonora con la de la zorra o el jilguero, para luego deducir, en letra cursiva, la moral fría y vana del apólogo. ${ }^{18}$

Esta rebelión contra la moraleja y la fábula la encontraremos en María Elena Walsh. ${ }^{19}$ Sin embargo, si bien tal postura responde en la juglaresa porteña en gran parte a su apego al nonsense, elemento esencial del folklore inglés al que ella adhiere y que mamó de su padre ${ }^{20}$, hay una comunidad de sentimiento en los dos escritores que estudiamos por una libertad creadora en relación también con las tradiciones populares, ajenas en general a toda actitud pedagógica e institucional.

Ahora bien, ¿qué elementos encontramos en la producción de María Elena Walsh que subrayen puntos de contacto con el universo juanramoniano ? La primera aproximación de la autora de El reino del revés con el público infantil se da a través de la poesía, que en un segundo paso se transforma en canción. Se trata de los libros Tutú Marambá (1960), El reino del revés (1963) y Zoo loco (1964). La Walsh mantiene su apego a la rima y al metro a lo largo de toda su vida ${ }^{21}$, y en ello se acerca no solamente al Juan Ramón más clásico sino a una escritora latinoamericana anterior, que fue también poeta y creadora de literatura infantil : Juana de Ibarbourou. 
El título mismo de Tutú Marambá con su sonoridad aguda y musical nos abre a un mundo extraño y folklórico. El prólogo nos dice : «Tutú Marambá es un duende brasileño y malo, según cuenta la leyenda. Se parece a nuestro 'cuco', al que por suerte ningún chico ha visto " (Walsh $2000: 7$ ). A partir de allí, la autora va a inventar un duende inspirado en la tradición popular; además abre su referencia folklórica a América Latina a través del Brasil sin ceñirse a lo local. Del mismo modo en que Jiménez coqueteaba con la tradición popular, integrándola en su obra a través de referencias y añadidos, María Elena Walsh se sirve de ella en Tutú Marambá incorporando fundamentalmente elementos rurales y norteños en un libro cuyo destinatario esencial será el niño de las ciudades. Textos como « Milonga del hornero », «Villancico norteño » (de marcado sincretismo, con un San José que toma mate) y « El charango » son extraordinarios intentos de integrar lo popular y de actualizar lo tradicional, de acercarlo a un público que lo tiene relativamente olvidado. En «Balada de Hormigón Armado» invierte el estereotipo de la hormiga trabajadora: Hormigón es despectivo, una hormiga es coqueta, otra, la protagonista, es una apasionada que muere de amor y la generalidad de las hormigas es solidaria. En ningún momento se habla de tareas o faenas. Evidentemente, este poema se erige en verdadera antifábula : se sabe que la hormiga de Esopo -que la Fontaine retoca- es egoísta y poco solidaria ${ }^{22}$, mientras que María Elena Walsh sitúa en el primer plano una solidaridad poco productiva financieramente; es el afecto lo que cuenta. Por otro lado, la frialdad de la hormiga de Esopo es sustituida aquí por insectos devorados por pasiones y muy poco previsores. Las hormigas de María Elena Walsh son cigarras y no extraña que la autora escriba años más tarde una verdadera oda a la cigarra y a la canción, en evidente contraste con las moralejas fabulísticas. ${ }^{23}$ En esto vemos la confirmación de una herencia juanramoniana.

Sin embargo el poema (y canción) más exitoso de Tutú Marambá quizá sea «La vaca estudiosa ». Verdadero preámbulo al Reino del revés, esta vaca representa una animalidad sabia frente a una humanidad alborotada e ignorante. Ciertamente, hay mucho de nonsense en la canción y sería incorrecto darle una interpretación moral y lógica al texto, pero no podemos olvidar uno de los capítulos de Platero y yo titulado «La miga » en que el poeta imagina al asno en la escuela (Jiménez 2005 : 96-97). Este capítulo no ha sido incluido en la versión para niños. La estampa le sirve a Jiménez para ridiculizar ciertos métodos de enseñanza y ciertos castigos elogiando una pedagogía próxima a la naturaleza. Platero aprenderá junto a las flores y las estrellas, y no será ese burro estereotipado en el rol que le asignan los hombres. Hay, en cierto sentido, alguna forma de reescritura en « La vaca estudiosa ».

Recorreré muy rápidamente $E l$ reino del revés. ¿Conocía María Elena Walsh las aleluyas y grabados que en España evocaban el tema del mundo al revés? En ellos se ven peces que vuelan y pájaros que nadan, como en el poema que da título al libro (Grant 1979). Seguramente Juan Ramón y Zenobia la habían acercado a esos documentos que tuvieron gran difusión popular. Otros poemas como « El sol », «La nena », « El mar » o « Un rey », herederos directos de las composiciones de Edward Lear en su The Book of Nonsense..., muestran un acercamiento ecléctico a todo tipo de literatura. ${ }^{24}$ María Elena Walsh no sólo compartía con Jiménez su gusto por el eclectismo, sino una proximidad evidente con la literatura de lengua inglesa. No olvidemos que apenas llegada a Riverdale, Juan Ramón le regala una antología de poesía norteamericana y que lo inglés está ya muy presente en el hogar de Ramos Mejía. Contrariamente a lo que se podría pensar, la abuela andaluza de María Elena no le transmitió el gusto por el folklore español (Dujovne 1982: 10), lo que nos hace pensar que esa herencia proviene del contacto con el poeta de Moguer y se 
consolida junto a Leda Valladares con quien ahonda el conocimiento del romancero, tan presente en su disco Canciones del tiempo de Maricastaña $a^{25}$ y en una música popular latinoamericana que se convierte en su heredera. Pinceladas de ese folklore aparecen en este libro, en poemas como la "Chacarera de los gatos », « Baguala de Juan Poquito » y las tres canciones de Navidad: «Zamba del niñito », "Tralalá de Nochebuena » y "Coplas para Navidad». Estas tres composiciones, tradicionales y renovadoras a la vez, cierran el libro y nos dejan un sabor final y duradero. A El reino del revés pertenece la más famosa de las canciones de la juglaresa, "Manuelita la tortuga ", que ya evoqué en otro trabajo (Copello : en prensa). La totalidad del libro entronca con Tutú Marambá por su estilo y por su espíritu, creando ya una estética propia.

El primer relato que escribe y publica nuestra escritora es Dailan Kifki (1966), historia de un elefante. Muy diferente de Platero y yo, tiene en común la presencia de una pareja conformada por un ser humano y un animal. Pero no es el único elemento que merece ser analizado. Si Juan Ramón opta por una geografía rural y aldeana, María Elena prefiere no exactamente la ciudad sino el suburbio puesto que buena parte de Dailan Kifki transcurre en Ituzaingó. ${ }^{26} \mathrm{En}$ ambos casos los autores van a integrar la lengua coloquial y popular. El acento andaluz aparece ya en el tercer capítulo de Platero a través de los niños pobres que se creen príncipes : «-Mi pare tié un reló e plata./ -Y er mío, un cabayo. / -Y er mío, una ejcopeta " (Jiménez 2005 : 93). En Dailan Kifki abundan las expresiones coloquiales o, a veces, resabios de canciones populares : «Estamos fritos » (p. 10, 15, 35, etc.), « haciendo pucheros » (p. 32), « se me ha perdido un bombero en el fondo del jardín » (p. 38), «y aquí no pasó nada » (p. 39), « la quinta queda donde el diablo perdió el poncho » (p. 53), « tenía las alas a la miseria » (p. 66), "mantantiru lirulá» (p. 139), etc. Todo ello lleva a un acercamiento al destinatario a través de una conciencia clara del género literatura infantil, que en Jiménez se va conformando con el tiempo, como por ejemplo cuando desea aligerar el léxico de Platero y yo en versiones ulteriores. ${ }^{27}$

El criterio de Juan Ramón Jiménez según el cual se niega a hacer de Platero el « héroe charlatán de una fabulilla " (Jiménez 2005: 237), se cumple perfectamente en Dailan Kifki. Si bien algunos animales hablan en la obra, esto suele ocurrir en el bosque de Gulubú, que es un lugar situado fuera de los mapas ${ }^{28}$; en el espacio real, Dailan Kifki es un animal que se expresa con ademanes, con llanto, a lo sumo con una curiosa piada cuando se encuentra arriba de un árbol (p. 26, 28), pero es fundamentalmente animal tierno, de miradas, como lo era Platero. También, como al asno andaluz, le gustan las flores que mira y que huele. ${ }^{29}$

31 No cabe duda de que María Elena Walsh pensó en Platero y yo al componer Dailan Kifki, no para imitarlo ni para parodiarlo, sino porque había en el libro del moguereño un modelo, unas sugerencias que llevaban a cierta concepción de la literatura infantil y que en parte tuvo en cuenta.

La incorporación de danzas y canciones folklóricas tampoco falta : por ejemplo cuando los embajadores bailan el carnavalito, el candombe, la cueca, la samba y el huaynito (Dailan Kifki, p. 43), o cuando el grillo Canuto canta una zamba que él mismo compuso y luego una chacarera (Dailan Kifki, p. 104, 105), o cuando la protagonista da unos pasitos de pericón por el andén de la estación de Ituzaingó (Dailan Kifki, p. 174)... Hay que subrayar que esta militancia por la música autóctona no desaparece en libros muy posteriores como Hotel Pioho's Palace que, aunque incluye computadoras y virus informáticos, permanece fiel a los resabios de lo folklórico. Cito por ejemplo esta estrofa de milonga : «Al fondo de Pioho’s 
Palace / me acuerdo cuando era pibe, / bailaban mucho candombe / alrededor de un aljibe » (Walsh $2002:$ 136).

Por todas estas razones, no podemos negar en la variopinta María Elena Walsh una deuda parcial con el espíritu de ese andaluz universal que compartió con ella los meses de Riverdale.

Me gustaría terminar con alguna referencia a Hecho a mano (1965) que constituye una etapa creativa extremadamente original y que clausura en nuestra autora la obra poética para adultos (aunque va integrando otros poemas en posteriores ediciones). Antonio Requeni define así la estética de este libro :

En Hecho a mano, María Elena incorporó a su verso el cuestionamiento social y el sarcasmo, elementos que enmascaraban pudorosamente el dolor al que su aguda sensibilidad la condenaba [...] Al mismo tiempo, su verso se allanaba, se despojaba de toda retórica, y la poeta encontraba sus temas en la inmediata cotidianeidad (Requeni 2008 : 725).

A través de un "Prólogo » en endecasílabos, la juglaresa define su poética, una poética que existe en un acercamiento a lo artesanal, al pueblo y a la infancia :

...que esta canción está toda hecha a mano.

Me gusta como al pueblo y a la infancia,

jugar con sonsonete de medida,

y entre la artesanía y la ignorancia,

por ahora me doy por aludida (Walsh $1999: 10$ ).

El libro no deja de explorar uno de los géneros mejor arraigados en la idiosincrasia del pueblo : la nana. Juan Ramón Jiménez se había sentido muy próximo a la nana. En uno de los cuadros de Platero y yo titulado «La arrulladora » describe a la hija de un carbonero que canta a su hermano pequeño la copla siguiente: «Mi niño se va a dormiii / en graaasia de la Pajtoraaa...[...] / y pooor dormirse mi niñooo, / se duermeee la arruyadoraaa... » (Jiménez 2005 : 140). Esa misma copla tomada de la tradición ya la había evocado en Pastorales (1903-1905), donde se interesa por las canciones de cuna (Jiménez 1965 : 55-56). Este gusto por la nana incorporada a la literatura de autor va a prender en Federico García Lorca, uno de los sucesores de Jiménez, quien también escribe su célebre conferencia Las nanas infantiles ${ }^{30}$ y que integra canciones de cuna en su teatro. El ejemplo más significativo quizá sea la copla que canta María Josefa en La casa de Bernarda Alba con una oveja en sus brazos. ${ }^{31}$ Hay ya allí una reelaboración completa de la nana, hecha de nonsense y de tragedia. En una corriente de acercamiento a lo popular también arraiga la canción de cuna en Juana de Ibarbourou, ese espíritu latinoamericano tan próximo a Juan Ramón y a Federico (Copello 2011). María Elena Walsh, por su parte, va a crear un poema absolutamente revolucionario en la tradición de la nana: "Canción de cuna " $^{32}$ que se transformará luego, abreviado, en la canción "Canción de cuna para gobernante" (Dujovne 1982: 177). El movimiento textual, que transforma las coplas (una forma de seguidilla ${ }^{33}$ ) en dísticos endecasilábicos con un verso al final en la versión cantada, enmascara el apego de la escritora al folklore. En efecto, la versión de Hecho a mano comienza con una estrofa tomada de la tradición popular, cuya estructura reproduce la autora en las estrofas siguientes :

$$
\begin{aligned}
& \text { Duérmete niño mío } \\
& \text { que viene el coco } \\
& \text { a llevarse a los niños } \\
& \text { que duermen poco. }
\end{aligned}
$$

Duerme tranquilamente, 
que viene un sable

a vigilar tu sueño

de gobernante...(p. 74) Walsh intenta devolver al pueblo a través de la canción en un paso posterior. Respetando uno de los caracteres básicos de la nana, que es la atmósfera de amenaza y de miedo ${ }^{34}$, la juglaresa latinoamericana construye un texto universal que nombra la tiranía y la indiferencia y lamenta las penas y el hambre :

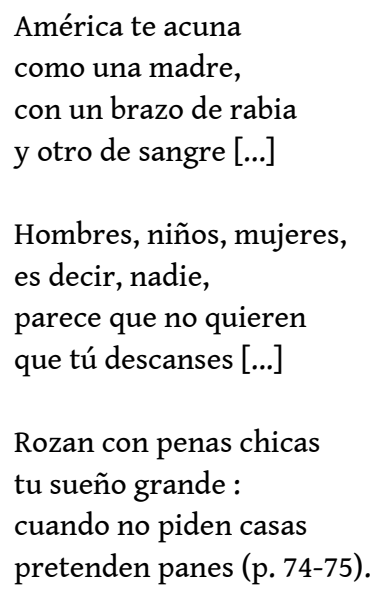

Este último ejemplo servirá de conclusión, de conclusión abierta ya que el poema merecería un análisis detenido. A pesar de ello, es posible ya afirmar que en los mecanismos creativos de María Elena Walsh hay a menudo una reescritura que proviene de las tradiciones populares. El dolor de la experiencia de Riverdale no puede ocultar lo que fue un encuentro hondo y fecundo. En efecto, un camino similar que va de la retórica a un acercamiento a lo esencial está en la base de los itinerarios de Juan Ramón Jiménez y María Elena Walsh. Los tiempos de Leda y María confirmarán aquellos hallazgos.

Pero «Canción de cuna para gobernante » muestra, más allá de los mecanismos creativos, la gran originalidad de la escritora de Hecho a mano. Amasando la arcilla de las arrulladoras elaboró un canto de denuncia y de alerta, invirtió perspectivas e hizo del discurso femenino (el de las nanas) el portavoz de una tristísima lucidez.

Y fueron madres las que no tanto tiempo después, en el pentagrama de la realidad, con sus pañuelos blancos, en pasos lastimosos de los jueves, transformaron sus propias canciones de cuna manchadas de muerte en iluminada esperanza.

\section{BIBLIOGRAFÍA}

Álvarez Pla, Bárbara. « Publican Vida, la autobiografía inédita de Juan Ramón Jiménez ». Clarín [Buenos Aires], 15 de enero de 2013, pp. 34-35.

Baehr, Rudolf. Manual de versificación española. Madrid : Gredos, 1973. 
Copello, Fernando. « À propos d'une berceuse de Juana de Ibarbourou : 'La loba, la loba...' dans l'Uruguay du XX'e siècle ». Publilije, II, 2011, WEB, 10, 3, 13.

Copello, Fernando. «Los itinerarios de la vida : distancias, atajos y vericuetos. A propósito de 'Manuelita la tortuga' de María Elena Walsh ». Chemins de traverse, Angers : Almoreal, sous presse.

Dandrey, Patrick. « Pour lire et comprendre (enfin ?) La Cigale et la Fourmi ». En : La fabrique des fables, Paris : Klincksieck, 2010, pp. 363-379.

Dujovne, Alicia. María Elena Walsh. Madrid : Ediciones Júcar, 1982.

Fernández Latour de Botas, O. Folklore y poesía argentina. Buenos Aires : Guadalupe, 1969.

García Lorca, F. (2009 a). La casa de Bernarda Alba. Edición de María Francisca Vilches de Frutos, Madrid : Cátedra, 2009.

García Lorca, F. (2009 b). Les berceuses. Paris : Allia, 2009.

Gaultier, Maud. « La fonction transgressive du disparate dans les livres pour enfants de María Elena Walsh ». En L. Aubage et al. (éd.). Les littératures d'Amérique latine au XXe siècle : une poétique de la transgression. Paris : L'Harmattan, 2009, pp. 187-196.

Grant, Helen F. « Images et gravures du monde à l'envers dans leurs relations avec la pensée et la littérature espagnoles ». En Lafond, Jean et Augustin Redondo (éds.). L'image du monde renversé et ses représentations littéraires et para-littéraires de la fin $d u X V^{e}$ siècle au milieu du XVII ${ }^{e}$. Paris : J. Vrin, 1979, pp. 17-33.

Heitzmann, Alfonso A. Juan Ramón Jiménez, 1956. Crónica de un Premio Nobel (memorias, cartas y documentos). Transcripción y notas de los telegramas y cartas de la segunda parte del libro : J. A. Expósito. Madrid : Publicaciones de la Residencia de Estudiantes, 2008.

Jiménez, Juan Ramón. Pastorales. Buenos Aires : Losada, 1965.

Jiménez, Juan Ramón. Platero y yo. Con cuadros cronológicos, introducción [...] a cargo de A. A. Gómez Yebra. Madrid : Castalia, 1992.

Jiménez, Juan Ramón. Platero y yo. Edición de M. P. Predmore. Madrid : Cátedra, 2005.

Lear, Edgard. The Book of Nonsense and Nonsense Songs [1845]. Londres : Penguin Books, 1996.

Luraschi, Ilse Adriana y Kay Sibbald. María Elena Walsh o el 'desafío de la limitación'. Buenos Aires : Sudamericana, 1993.

« María Elena Walsh, la del establishement », Primera Plana [Buenos Aires], 15 de agosto de 1972, pp. 38-39.

Monteiro Lobato, J.. Reinaçoes de Narizinho. São Paulo : Companhia Editora Nacional, 1937.

Morán Rodríguez, Carmen. "Juan Ramón e Hispanoamérica ». En : Catálogo de la Exposición "Juan Ramón Jiménez. Premio Nobel 1956”. Pabellón Transatlántico, Residencia de Estudiantes, Madrid : Publicaciones de la Residencia de Estudiantes, 2006, pp. 445-475.

Palau de Nemes, Graciela. Vida y obra de Juan Ramón Jiménez. Madrid : Gredos, 1957.

Porrúa, María del Carmen. « Juan Ramón en Buenos Aires (agosto-noviembre 1948) ». Filología, LX, 2008, pp. 121-133.

Requeni, Antonio. «Juan Ramón Jiménez en la Argentina ». Los Andes [Mendoza], 20 de junio de 1982, 3ª Sección, p. 1.

Requeni, Antonio. « La poesía de María Elena Walsh ». Boletín de la Academia Argentina de Letras, vol. 73, $\mathrm{N}^{\circ}$ 299-300, 2008, pp. 721-730. 
Sánchez García, Raquel y Ana Martínez Rus. La lectura en la España contemporánea. Madrid : Arco Libros, 2010.

Walsh, María Elena. Dailan Kifki. Ilustraciones de Eduardo Fuhrmann y Ricardo Fuhrmann. Buenos Aires : Espasa-Calpe, 1998.

Walsh, María Elena. Desventuras en el País-Jardín-de-Infantes. Buenos Aires : Sudamericana, 1993.

Walsh, María Elena (2008 a). El reino del revés. Ilustraciones de Nora Hilb. Buenos Aires : Alfaguara, 2008.

Walsh, María Elena (2008 b). Fantasmas en el parque. Buenos Aires : Alfaguara, 2008.

Walsh, María Elena. Hecho a mano [1965]. Buenos Aires : Seix Barral, 1999.

Walsh, María Elena. Hotel Pioho's Palace. Ilustraciones de Lancman Ink. Buenos Aires : Alfaguara, 2002.

Walsh, María Elena. «Juan Ramón Jiménez, Premio Nobel ». Sur, 244, enero-febrero de 1957, pp.1-4.

Walsh, María Elena. Tutú Marambá. Ilustraciones de Nancy Fiorini. Buenos Aires : Alfaguara, 2000.

\section{NOTAS}

1. Vaya mi agradecimiento a Aura Díaz-López, bibliotecaria jefe de la Sala Zenobia y Juan Ramón Jiménez de la Universidad de Puerto Rico, y a Antonio Requeni, con quien mantuve durante la redacción de este trabajo un nutrido intercambio epistolar.

2. JRJ es uno de aquellos peninsulares que se dejan influenciar por la literatura hispanoamericana y que inauguran, en este sentido, una verdadera corriente de intercambio dentro del universo de la literatura de lengua española. Es un hecho que se debe tener en cuenta a la hora de analizar su relación con MEW. Otro rioplatense, José Enrique Rodó, había despertado tempranamente en JRJ lecturas y amistades.

3. Véase Porrúa $(2008: 122,124)$ y Requeni $(2008: 721)$.

4. Este documento fotográfico pertenece a la Sala Zenobia y Juan Ramón Jiménez, Sistema de Bibliotecas de la Universidad de Puerto Rico, Recinto de Río Piedras, institución que nos autoriza a publicarlo en este trabajo. Se encuentran también en la fotografía Edgar Podestá, Alberto Greco, Hugo Ezequiel Lezama y Javier Fernández. En diálogo con Horacio Armani deduce Antonio Requeni que la otra muchacha probablemente sea Carmen Córdova de la Serna, hija del crítico de arte Córdova Iturburu y prima hermana del Che Guevara. MEW y Carmen Córdova eran muy amigas por ese entonces (carta del 18 de marzo de 2013).

5. También recuerda a JRJ en Novios de antaño (Buenos Aires : Sudamericana, 1990) donde integra palabras del escritor de Moguer en medio de los fragmentos de infancia evocados: «allá en el fondo del gran jardín de nuestro olvido » (p. 121) y « en un arruinamiento de ruinas » (p. 125).

6. Este artículo puede leerse hoy en Desventuras en el País-Jardín-de-Infantes, (Walsh 1993 : 88-90) ; la publicación del original está fechada en julio de 1949.

7. «En 1961 muere su madre, y esta desgracia la lleva a una depresión y al consiguiente tratamiento [...] Es curioso que a partir y durante este penoso proceso interior se haya dedicado a producir sus obras más luminosas... » (Dujovne 1982 : 85).

8. Ese dolorido sentir, esa incomodidad con respecto al maestro, aparece también en la carta de pésame dirigida a JR por la muerte de Zenobia : hay allí un sentimiento retenido, una dificultad evidente. La carta está fechada en Tucumán el 30 de octubre de 1956 (Zenobia murió el 28 de octubre, tres días después de la atribución del Premio Nobel de Literatura a su marido) y dice así : 
«Querido Juan Ramón, / Ahora más que nunca inútil para comunicarme con usted, sólo quiero decirle que comparto hasta el llanto su dolor, que quisiera darle un abrazo con todo mi cariño y mi inmensa admiración por su vida. / Después de haber andado mucho por el mundo, he valorado más que nunca a usted y a la querida Zenobia. Para ella guardo el más conmovido recuerdo. Y a usted, mi querido Juan Ramón, pienso volver a encontrarlo alguna vez, sobre la imagen de las primaveras ya rotas de Maryland. / Con gratitud eterna, con el cariño más hondo lo abraza su amiga / María Elena Walsh » (carta manuscrita, en Heitzmann 2008 : 378 ; el subrayado es mío).

9. El encuentro con Leda Valladares en Panamá, desde donde van a París, y la larga estancia de cuatro años en la capital francesa, donde difunden el folklore andino es anterior a la redacción del artículo de Sur, cuando MEW ya ha vuelto a la Argentina y se sigue dedicando a la difusión del folklore tanto andino como español (Dujovne 1982 : 45-72 ; Luraschi y Sibbald 1993 : 29-39).

10. «La poesía en la primera infancia » (Walsh 1993 : 119-127).

11. Tampoco menciona MEW a Chico Carlo de Juana de Ibarbourou, libro demasiado asociado al currículo escolar. Sin embargo, su simpatía por la escritora uruguaya es evidente y la nombra al correr de la conversación con A. Dujovne mencionando su poema « La Higuera » (Dujovne 1982 : 66).

12. Me serviré para ello de la edición de Cátedra de Michael Predmore con varios apéndices (Jiménez 2005). Sin embargo, por su conocimiento de la literatura infantil y por sus comentarios extremadamente atinados, recurriré también a la introducción de Antonio A. Gómez Yebra en la edición de Castalia (Jiménez 1992).

13. Véase el texto « Platero español en Francia » (Jiménez $2005: 269-271)$.

14. Por ejemplo, la clásica versión de Losada (1970), que se difundió durante años, contiene 68 capítulos y una despedida (en lugar de los 136 de la versión completa)

15. Durante los años de la guerra civil, en las zonas dominadas por la falange, Platero y yo fue considerado por las autoridades como libro pernicioso y estuvo prohibido (Sánchez García y Martínez Rus 2010 : 75).

16. «Y pensé, de pronto, en Platero, que, aunque iba debajo de mí, se me había, como si fuera mi cuerpo, olvidado. » (Jiménez $2005: 116$ ).

17. Como se refleja en este texto de JRJ destinado al prólogo de un libro de Paulita Brook : «Y lo extraordinario es que no se les ocurra que a tí, burro, a los burros, a los caballos, a los perros, a los toros, que tienen tanta fuerza y estarían para ellos en la cumbre de la escala macho, os gusta también todo eso tan delicado que a mí me gusta, y no se avergüenzan de ello. Lo delicado, Platero, ¡qué problemita! » (Jiménez $2005: 268$ ).

18. Jiménez $2005: 237$. El subrayado es nuestro. Se trata de un capítulo polémico que no figura en la versión para niños, pero que expresa con claridad una estética nueva.

19. Un artículo virulento y anónimo publicado en Primera Plana en 1972 confirma y matiza esta percepción ya desde su título « María Elena, la del establishment ». El documento interesa porque evoca la existencia en la Argentina de 1972 de una polémica en torno a la función moral de la literatura infantil : si bien, según el anónimo autor, MEW no encarna una renovación total, está sí en el camino de un cambio y eso es evidente.

20. «[El padre] tocó para ellos el piano, el violoncelo y el mandolín y les cantó Yes, we have no bananas y les legó una variada gama de amores, que van de Dickens a Josephine Baker, de las Nursery Rhymes a los ilusionistas de circo [...] en su casa, el nonsense era un juguete mil veces preferible a las muñecas de trapo " (Dujovne 1982: 12). Sobre la función del disparate en MEW, véase Gaultier (2009).

21. Así lo explica A. Dujovne : « [MEW] Dice que las rimas la persiguen, que la atraía la magia que se produce dentro de esas formas, asociaciones inesperadas con lo onírico y lo inconsciente. La atraían las cárceles, o esa suma de limitaciones que para otros representan cárceles » (Dujovne $1982: 18)$. 
22. Véase al respecto Dandrey 2010 : 363-379. Ya había reaccionado contra la moral esópica un escritor latinoamericano de literatura infantil, José Monteiro Lobato, dándole un segundo final a la fábula de la hormiga (Monteiro Lobato $1937: 201$ ).

23. «Tantas veces me mataron, / tantas veces me morí, / sin embargo estoy aquí / resucitando. / Gracias doy a la desgracia / y a la mano con puñal / porque me mató tan mal, / y seguí cantando. / Cantando al sol como la cigarra..." (citado por Dujovne 1982: 172). También la "Canción de Titina », en El reino del revés, muestra a una hormiga a quien en lugar de trabajar, le encanta bailar chamamés (Walsh 2008 a : 48-49).

24. Véanse el espíritu y la forma respetuosa de la estructura de los poemas del inglés (Lear [1845] 1996).

25. Son interesantes sus comentarios en la conferencia « Dina Rot y la canción sefardí »: «Estos romances judeo-españoles son origen de toda la música popular hispanoamericana [...] Este romancero es gajo del monumental romancero español, canciones de madre de toda la gran poesía española, desde Manrique hasta García Lorca. Fue el amor de Juan Ramón Jiménez que inspiró a Manuel de Falla una nueva dimensión para la música culta española... » (Walsh 1993 : 138-142: 139, 141).

26. Aunque la casa de la protagonista (sin nombre) queda en el barrio de Palermo, el relato es itinerante (Walsh 1998 : 175).

27. Así lo dice JRJ en carta a Carmen Laforet enviada desde Washington en 1946 (Jiménez 1992 : 295).

28. «El bosque de Gulubú no figura en los mapas... » (Walsh 1998 : 87).

29. «Dailan Kifki se quedó quieto en el jardín, mirando y oliendo las flores” (p. 8) ; « Allí lo dejé charlando con las flores y las hormigas... » (p. 175).

30. Consulto la edición bilingüe de Line Amselem: García Lorca 2009 a. Pronuncia esta conferencia en 1928 en Madrid en la Residencia de Estudiantes, luego en 1930 en Nueva York y en La Habana (p. 77).

31. « Ovejita mía, niño mío, / vámonos a la orilla del mar. / La hormiguita estará en su puerta, / yo te daré la teta y el pan » (García Lorca 2009 b, p. 268).

32. Walsh 1999: 74-76. La sensibilidad de MEW hacia la canción de cuna se manifiesta tempranamente en este episodio ocurrido a su llegada a los Estados Unidos y que cuenta en «Carta de Maryland» (1949) : «Por fin me encontré instalada en el tren de Washington, donde hice mi primer conocimiento del pueblo. Entablé muchas conversaciones [...] Cerca viajaban dos madres jóvenes, con sendos chiquillos rubios sorbiendo un higiénicamente envasado chocolate. Fue una gloria oír las primeras canciones de cuna y los primeros balbuceos vivos en el idioma de la tierra recién entrevista » (Walsh 1993 : 88).

33. Se trata de estrofas de cuatro versos con la estructura siguiente : heptasílabo / pentasílabo / heptasílabo / pentasílabo ; y con rima asonante en los versos pares. Sobre las formas variadas de la seguidilla véase Baehr 1973 : 247-258.

34. En su conferencia sobre las nanas, García Lorca evoca a esas mujeres del pueblo que deseando que sus hijos duerman recurren a personajes amenazadores como el cuco, el toro o la loba... (García Lorca 2009 b : 36). 


\section{RESÚMENES}

El encuentro entre Juan Ramón Jiménez y María Elena Walsh en 1948-1949 ha dejado sin duda huellas en la producción literaria de la escritora argentina.

La rencontre entre Juan Ramón Jiménez et María Elena Walsh en 1948-1949 a sans doute laissé des traces dans la production littéraire de l'écrivaine argentine.

María Elena Walsh met Juan Ramón Jiménez in 1948-1949 and this experience must have marked the literary production of the argentine writer.

\section{ÍNDICE}

Mots-clés: Juan Ramón Jiménez, María Elena Walsh, culture savante et culture populaire, berceuse, représentation animale

Keywords: learned culture and popular culture, lullaby, zoomorphic representation

Palabras claves: cultura letrada y cultura popular, la nana, representación de animales

\section{AUTOR}

\section{FERNANDO COPELLO}

Université du Maine-Le Mans. Labo 3L.AM

Fernand.Copello@univ-lemans.fr 